\title{
Tyrosinase Inhibitory Effect, Antioxidant and Anticancer Activities of Bioactive compounds in Ripe Hog Plum (Spondias pinnata) Fruit Extracts
}

\author{
SUPAWADEE PATATHANANONE ${ }^{1 *}$, JUREERUT DADUANG ${ }^{2}$, \\ AMONRAT KORANEEKIJ ${ }^{2}$ and CHIA-YING LI ${ }^{3}$
}

\author{
1Department of Chemistry, Faculty of Science and Technology, Rajamangala University of Technology \\ Thanyaburi, 39 Moo 1, Rangsit-Nakhonnayok Rd., Klong 6, Thanyaburi, Pathum Thani, 12110, Thailand. \\ ${ }^{2}$ Department of Clinical Chemistry, Faculty of Associated Medical Sciences, Khon Kaen University, \\ Khon Kaen 40002, Thailand. \\ ${ }^{3}$ Department of Applied Chemistry, National Pingtung University. No.1, Linsen Road., Pingtung City, \\ Pingtung Country 90003, Taiwan. \\ ${ }^{*}$ Corresponding author E-mail: Supawadee_P@ rmutt.ac.th \\ http://dx.doi.org/10.13005/ojc/350302
}

(Received: April 12, 2019; Accepted: May 13, 2019)

\begin{abstract}
The usage of ripe hog plum fruit (Spondias pinnata) extracts in cosmetics and food products, including cancer therapeutic agents have a few studies. Herein the strong anti-tyrosinase activity found in the extracted part of isopropanol is reported. This extract was separated by liquid/liquid extraction using hexane: methanol $+\mathrm{H}_{2} \mathrm{O}$. The hydrophilic layer $\left(6 \mathrm{~A}^{*}\right)$ exhibited the anti-tyrosinase, antioxidant and anticancer activities In vitro. The $\mathrm{IC}_{50}$ value of each bioactivity was presented as approximately $0.18,0.04$, and $1.40 \mathrm{mg} / \mathrm{ml}$, respectively. In addition, $6 \mathrm{~A}^{*}$ fraction showed a very low cytotoxic effect in normal fibroblast cells (NHDF cells). The bioactive agents in $6 \mathrm{~A}^{*}$ were purified by $\mathrm{C} 18$ reverse-phase High-Performance Liquid Column Chromatography (HPLC). The 12 purified peaks were shown in the chromatogram profile. All peaks (excepted 6A-06 and 6A-09) displayed anti-tyrosinase activity, whereas the antioxidant property was not found in $6 \mathrm{~A}-01,6 \mathrm{~A}-06$, and $6 \mathrm{~A}-08$ but was represented in other peaks. Most purified peaks were indicated to be the aromatic alcohol or derivative phenol compounds.
\end{abstract}

Keywords: Phenolic acid, Flavonoid, Tyrosinase inhibitor, Cytotoxic effect, Wild mango.

\section{INTRODUCTION}

Aging is a normal situation of human life associated with two major factors: (1) intrinsic (decreasing hormone, increasing age, etc.) and (2) extrinsic factors (sunlight, smoking, etc.). In particular, reactive oxygen species (ROS) production increases in cells associated with the ultraviolet radiation from sunlight. ROS is a group of free radicals that enhance the activity of elastase, collagenase, and hyaluronidase enzymes. These enzymes can degrade the structural components of extracellular

This is an Open Access article licensed under a Creative Commons license: Attribution 4.0 International (CC- BY). Published by Oriental Scientific Publishing Company (c) 2018 
matrix (elastin, collagen, hyaluronic acid) in cells, changing the physiological and progressive structure of the skin ${ }^{1}$. Moreover, tyrosinase, which is the key enzyme in the melanogenesis process, can be induced directly by sunlight; excessive exposure to sunlight can promote hyperpigmentation of the skin. ${ }^{2,3}$

There are two goal targets for decreasing the causes of aging skin: (1) inhibiting the enzyme activity and (2) decreasing oxidative stress by antioxidant agents. ${ }^{1}$ Furthermore, the active elements should be safety, insufficient side effects, and nontoxicity ${ }^{4}$. Plants have been long reported to be used in the dietary life of humans. Plant metabolites are synthesized for use in several survival mechanisms, including defending against attacks from predators ${ }^{5}$. Phytochemicals are a large group of plant-derived substances that consist of two types of metabolites, primary and secondary metabolites ${ }^{6}$. The primary metabolites are found in all plants, whereas secondary metabolites are synthesized for specific functions such as reducing oxidative stress and protecting plants from infection ${ }^{7}$. Interestingly, plant metabolites are used in the development of many products that depend on the bioactivities of each compound. In particular, traditional medicinal plants have been important sources for identifying the compounds that have potential to be drugs, including bioactive agents used as the active ingredients in food preservatives and cosmetic products ${ }^{8}$.

Hog plum, or wild mango, is the general name of the genus Spondias, which consists of 18 species and is classified as part of the Anacardiaceae family ${ }^{9}$. The members of this genus have been used comprehensively in traditional medicine to treat many diseases. The pharmaceutical properties of the members show antioxidant ${ }^{10}$, anti-inflammatory ${ }^{11}$, antimicrobial ${ }^{12}$, anti-arthritic, antipyretic, antifertility, antihypertensive, anticancer, hepatoprotective, hypoglycemic, and photoprotective effects. ${ }^{9}$ The Spondias pinnata is a species of the genus Spondias. ${ }^{9}$ Its native origin area is in Southeast Asia, including Thailand. The common name of $S$. pinnata in Thai is Makok. Recently, $S$. pinnata was a famous plant used in traditional foods in the northeastern area of Thailand, especially papaya salad and spicy foods. It was also used as an ingredient in traditional medicine. Moreover, in India, powdered ripe fruits of $S$. pinnata were used as an antidote for poison arrows. ${ }^{9}$ Researchers have reported that $S$. pinnata was a source that contained different classes of secondary metabolites. The methanolic extract of S. pinnata bark was found to be methyl gallate, which is able to induce apoptotic cell death in human glioblastoma, lung, and breast cancer ${ }^{13}$. Furthermore, the chloroform/methanol extracts of S. pinnata bark exhibited ergosteryl triterpenes I and $\mathrm{II}^{14}$. The methanolic extract of the $S$. pinnata fruit contained triterpenoid substances such as $\beta$-amyrin and oleanolic acid ${ }^{15}$. The aerial parts of $S$. pinnata extracted by ethanol were found to include many kinds of sterols ( $\beta$-sitosterol, and $\beta$-sitosterol $\beta$-D-glucoside, lignoceric acid, and stigmast-4en-3-one, 24-methylenecycloartanone). ${ }^{9}$ However a few researchers studied the anti-tyrosinase, anti-elastase and anticancer activity on oral carcinoma cells from ripe hog plum (S. pinnata) fruit extracts. Additionally the applications of ripe hog plum fruit extracts in cosmetic and food preservative products have not been reported. Therefore, the aim of this study was to extract the bioactive compounds from ripe hog plum (S. pinnata) fruit and to determine the anti-tyrosinase and cytotoxic activity in oral carcinoma (KB cells), including the cytotoxic effects in normal fibroblast cells (NHDF cells). Moreover, the bioactive agents were separated and purified by $\mathrm{C} 18$ reverse-phase HPLC. The purified peaks were analyzed for anti-tyrosinase and antioxidant properties, including the possibility of phytochemical types and their structures, through thin-layer chromatography and ${ }^{1} \mathrm{H}$ NMR.

This report indicated that ripe hog plum fruit is a source of bioactive components that display the ability of anti-tyrosinase, including antioxidant and anticancer activities. This report is the first to use ripe wild mango fruit to extract the bioactive agents, as well as the first report to find the anti-tyrosinase activity of these extracts. Interestingly these compounds showed very low cytotoxic effect in NHDF cells. Most of the bioactive agents contained in this extract are part of the group of polyphenolic compounds. In particular, gallic acid and gallic glycoside are substances indicated in this extract part. Previously, reports showed that gallic acid is a safety agent used for food additives ${ }^{23}$ and as an anticancer agent ${ }^{32}$. Therefore, the safety of the agents in the $6 \mathrm{~A}^{*}$ fraction could be developed to be the active ingredients in food and cosmetic products, including cancer therapeutic agents in the future. 


\section{MATERIALS AND METHODS}

\section{Chemicals and Reagents}

Mushroom tyrosinase was bought from

Sigma Aldrich. L-Dopa and kojic acid were purchased from Himedia company. Dimethyl sulfoxide, folin ciocalteu reagent, trypan blue, Dulbecco's Modified Eagle Medium-high glucose (DMEM-Hg), fetal bovine serum (FBS), L-glutamine, penicillinstreptomycin, and trypsin-EDTA were ordered from Gibco BRL (Grand Island, NY, U.S.A). Additionally, 3-[4, 5-dimethylthiazol-2-yl]-2-5-diphenyltetrazolium bromide (MTT) and 2,2-diphenyl-1-picrylhydrazyl were bought from Invitrogen (Carlsbad, CA).

\section{Extraction Procedure}

Ripe hog plum fruits were collected from the northeastern area of Thailand. They were washed with water including $70 \% \mathrm{v} / \mathrm{v}$ ethanol 3 times. Then, the cleaned fruits were dried in the air. Next, peel and pericarp were collected and homogenized using a homogenization machine. The homogenate was frozen dry in a freeze dryer. Approximately 200.0 $\mathrm{g}$ of dried powder was placed into the chambers, and hexane was added at a ratio of $1: 4 \mathrm{w} / \mathrm{v}$. The extracted chambers were shaken at $180 \mathrm{rpm}$ for 72 hours. The supernatant was collected and filtrated by Whatman No. 1. The precipitant was extracted continuously using ethyl acetate, isopropanol and ethanol, respectively using the same process of the hexane extraction. The schematic diagram of the extraction step is shown in Fig. 1. All supernatant parts of each extraction solvent were evaporated using an evaporator. The extracts were named WMRI_Hexane, WMRI_Ethylacetate, WMRI_ Isopropanol, and WMRI_Ethanol, respectively. Then, the inhibitory effect of these treatment samples on tyrosinase enzyme was determined.

\section{Liquid/Liquid Extraction}

The extract, WMRI_Isopropanol, was collected to extract the bioactive agents by liquid/ liquid extraction ${ }^{16}$. Approximately $10.0 \mathrm{~g}$ of this extract (WMRI_Isopropanol) was dissolved by hexane and placed into a separatory funnel. Next, methanol, which was added to a mini volume of the water, was subjected and mixed gently. The separatory funnel stood for 30 minutes. After that, the methanol layer was collected to evaporate and lyophilize. This part of the treated sample was called $6 A^{*}$ fraction. The biological properties and types of bioactive substances will be analyzed in the following procedure.

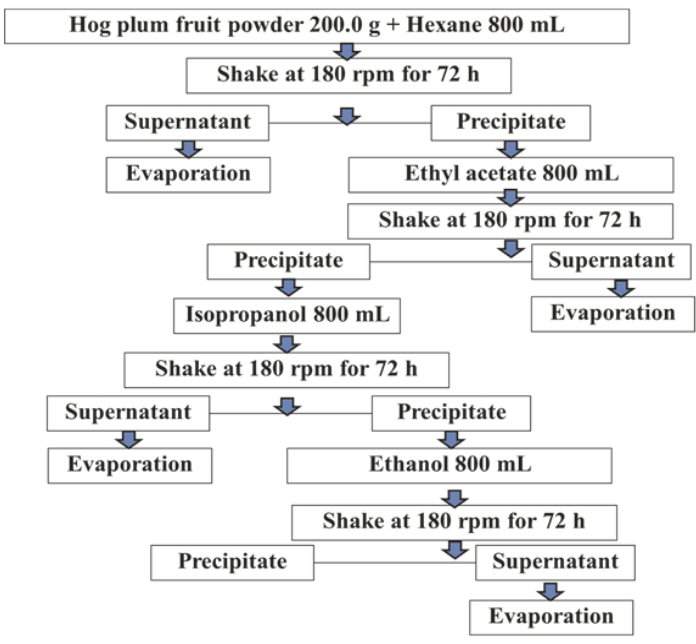

Fig. 1. The schematic diagram of the ripe hog plum fruit extraction process. The extracts were named according to the solvent system used for the extraction procedure. The ID names of the extracts were WMRI_Hexane,WMRI_Ethylacetate,WMRI_ Isopropanol, and WMRI_Ethanol

\section{Anti-tyrosinase Activity Assay}

The inhibition tyrosinase activity effect was determined by the dopachrome method according to the modified procedure ${ }^{17}$. The reaction was conducted in a 96-well microplate. Kojic acid was used as a positive control. Firstly, the tyrosinase enzyme was preincubated with the varying concentrations of treatment samples. The $10.0 \mu \mathrm{g} / \mathrm{ml}$ of mushroom tyrosinase in $50 \mathrm{mM}$ phosphate buffer $\mathrm{pH} 6.8(100 \mu \mathrm{l})$ and $70 \mu \mathrm{l}$ of deionized water were placed into wells of 96-well plate. Then, $10.0 \mu \mathrm{l}$ of treatment samples were subjected and mixed with the enzyme. The plate was incubated at $37^{\circ} \mathrm{C}$ for 10 minutes. Next, $10.0 \mu \mathrm{l}$ of 20.0 $\mathrm{mM}$ L-Dopa in $50 \mathrm{mM}$ phosphate buffer $\mathrm{pH} 6.8$ was added to the well and mixed gently. The plate was incubated at $37^{\circ} \mathrm{C}$ for 20 minutes. The absorbance value was measured at the wavelength of $495 \mathrm{~nm}$ of a microplate reader (EZ-Read 2000, Biochrome, U.S.A). The percentage of tyrosinase inhibitory activity of test substances was calculated according to the method described by Long et al., (2002).

\section{Antioxidant activity assay}

The $6 A^{*}$ fraction and the purified peaks were determined the antioxidant activity using a modified DPPH assay. The conditions of the analysis were conducted in a 96-well plate. Approximately $190 \mu \mathrm{l}$ of the $0.10 \mathrm{mM}$ DPPH solution was placed into each well. After that $10 \mu \mathrm{l}$ of the different concentrations of treatment samples and DMSO, 
which was used as the negative control were added to the DPPH solution and mixed gently. The plate was incubated at $37^{\circ} \mathrm{C}$ for 30 minutes in the dark. Next the absorbance value of each condition was measured at the wavelength of $515 \mathrm{~nm}$ using a microplate reader. The percentage of antioxidant activity was numbered using the equation previously described by Chen et al., (2010). ${ }^{18}$

\section{The Cytotoxicity Assay}

The cell viability assay most commonly used throughout the world is the 3-(4, 5-dimethylthiazol2-yl)-2, 5-diphenyltetrazolium bromide or MTT assay previously described by Mossmann (1983). ${ }^{19}$ Herein, the epidermal carcinoma of the mouth (KB cells) and NHDF cells were placed in $25 \mathrm{~cm}^{2}$ tissue culture flasks at $37^{\circ} \mathrm{C}$ with $5 \% \mathrm{CO}_{2}$ in DMEMHG media supplemented with $10 \%$ fetal bovine serum and $1.0 \%$ penicillin-streptomycin $(10,000$ $\mathrm{U} / \mathrm{ml}$ penicillin and $10 \mathrm{mg} / \mathrm{ml}$ streptomycin). Once the cells were approximately $70 \%$ confluent, they were trypsinized with $1 \mathrm{ml}$ of $1 \mathrm{X}$ trypsin-EDTA, incubated at $37^{\circ} \mathrm{C}$ for $5 \mathrm{~min}$, and centrifuged at $1,500 \mathrm{rpm}$ for 5 minute. The supernatant was removed, and 200 $\mu \mathrm{l}$ of seeding cells were re-suspended in $2 \mathrm{ml}$ of DMEM-HG media. Approximately $9 \times 10^{3}$ cells were seeded in each well of the 96-well tissue culture plate and incubated under the same conditions for 24 hours. Next, cells were treated with various final concentrations of $6 A^{*}(0.5-2.0 \mathrm{mg} / \mathrm{ml})$ and incubated at $37{ }^{\circ} \mathrm{C}$ for 24 and 48 hours. After that, $100 \mu$ of 5.0 $\mathrm{mg} / \mathrm{ml}$ MTT solution in $1 \mathrm{XPBS} \mathrm{pH} 7.4$ was added to the wells and incubated for 4 hours. Then, the MTT solution was removed. The solubilizing solution of formazan was subjected in each well and incubated at room temperature or $37^{\circ} \mathrm{C}$. The dissolved formazan was measured for absorbance at 570 $\mathrm{nm}$. The percentage of cells viability was calculated according to the formula (see formula below) as described by Patathananone et al., (2016) ${ }^{20}$.

$\%$ Viability cells $=\frac{(\text { Ab value of sample }- \text { Ab value of the blank }) \times 100}{(\text { Ab value of control }- \text { Ab value of the blank })}$

\section{Thin Layer Chromatography}

The treatment samples of $6 \mathrm{~A}^{*}$ and gallic acid were dissolved in methanol. Both samples were spotted on a silica sheet. Next, the mobile phase (chloroform: methanol: $\mathrm{H}_{2} \mathrm{O} ; 1: 1: 0.0005$ ) was placed into the chamber and incubated for 5 minute. The stationary phase was put in the chamber and separated until the finish, and then it was incubated in the oven at $105^{\circ} \mathrm{C}$ for 10 minutes. The process of development was designed under the condition of $\mathrm{KMnO}_{4}, 12 \% \mathrm{v} / \mathrm{v} \mathrm{H}_{2} \mathrm{SO}_{4}$, and $0.05 \%$ $\mathrm{v} / \mathrm{v}$ Anisaldehyde in acid methanol. The separated sheets were sprayed with each developing solution. Finally, separated TLC sheets were placed in an oven at $105^{\circ} \mathrm{C}$ for $10 \mathrm{~min}$ minutes to promote the spotting of the compounds.

\section{Purification active bioactive compounds by C18 reverse phase high pressure liquid column chromatography \\ The treatment sample $6 A^{*}$ was dissolved} in $30 \% \mathrm{v} / \mathrm{v}$ methanol in deionized water and filtrated using a $0.45-\mu \mathrm{m}$ syringe filter membrane. The column was incubated in $30 \% \mathrm{v} / \mathrm{v}$ methanol for $15 \mathrm{~min}$ at a flow rate of $3.0 \mathrm{ml} / \mathrm{minute}$. The $500 \mu \mathrm{l}$ of the sample was injected into the $\mathrm{C} 18$ reverse-phase column (VP250/10 Nucleodur C18 HTEC, $5 \mu \mathrm{m}$ ) and separated by HPLC (shimadzu, Model SPD-20A) under the time program shown in Table 1. Absorbance values of each peak were determined at $220 \mathrm{~nm}$ and $270 \mathrm{~nm}$. Next, the purified peaks were collected and evaporated to determine tyrosinase inhibitory effect and ${ }_{1}^{1} \mathrm{H}$ NMR in the next procedure.

\begin{tabular}{|c|c|c|}
\hline Times (min) & Solvent system (\%) & Processing \\
\hline 15 & $\begin{array}{c}30 \% \text { v/v solvent B } \\
\text { Load /Injection sample }\end{array}$ & equilibration \\
\hline $0-30$ & $30 \% \mathrm{v} / \mathrm{v} \rightarrow 50 \% \mathrm{v} / \mathrm{v}$ solvent $\mathrm{B}$ & Run \\
\hline $30-40$ & $50 \% \mathrm{v} / \mathrm{v} \rightarrow 100 \% \mathrm{v} / \mathrm{v}$ solvent $\mathrm{B}$ & Run \\
\hline $40-50$ & $100 \% \mathrm{v} / \mathrm{v}$ solvent B & Run \\
\hline 50 & Stop run & \\
\hline
\end{tabular}

Determination of phytochemicals, including the aromatic alcohols and phenol derivatives

The phenolic component in these purified peaks was analyzed by modified total phenolic content method $^{21}$. The experiment was set in a small volume of the reagent and showed the changing result on the silica sheet. Gallic acid and quercetin were used as the positive of phenolic and flavonoid standard compound, respectively. On the other hand, methanol was subjected to indicating as the negative control. Purified samples and control agents $(10.0 \mu \mathrm{l})$ were placed into each well of 96 -well plate. Then, $10.0 \mu$ of $2.0 \% \mathrm{w} / \mathrm{v} \mathrm{Na}_{2} \mathrm{CO}_{3}$ was added into wells. After that, 10.0 $\mu \mathrm{l}$ of diluted folin reagent was subjected and mixed. 
The plate was incubated in the dark for 20 minutes. Approximately $5.0 \mu \mathrm{l}$ of each reaction was dropped on a silica sheet and dried at room temperature. The phenolic compounds were indicated by the blue-black, blue-green, and green color associated with the concentration of the agents.

Determination the structure of purified $6 \mathrm{~A}-03$ peak by Proton Nuclear magnetic resonance

${ }^{1} \mathrm{H}$ NMR spectra were recorded on JNM$\mathrm{CRZ} 400 \mathrm{MHz}$ spectrometers using tetramethylsilane (TMS) as the internal standard. The sample was dissolved in 0.6 mL DMSO- $d_{6}$ for analysis. All chemical shifts are reported in parts per million (ppm, $\delta$ ).

\section{Statistical analysis}

The data of anti-tyrosinase activity and the cytotoxic activity assay were examined and carried out in triplicate. Statistical analysis of variance (ANOVA) was applied to evaluate the data.

\section{RESULTS}

Inhibition Tyrosinase Activity of Crude Extracts Ripe wild mango powder was extracted using the solvent system: hexane, ethyl acetate, isopropanol, and ethanol. These extracts were called WMRI_Hexane, WMRA_Ethyl acetate, WMRI_ Isopropanol, and WMRI_Ethanol, respectively. The extracts were treated at $0.2-2.0 \mathrm{mg} / \mathrm{ml}$. These results are presented in Fig. 2. All treatment samples showed tyrosinase inhibitory activity. The percentage of tyrosinase inhibition of WMRI_Hexane and WMRA_Ethyl acetate was less than $40 \%$. Both extracts might have an $\mathrm{IC}_{50}$ value higher than $2.0 \mathrm{mg} / \mathrm{ml}$. Additionally, WMRI_Isopropanol extract presented strong anti-tyrosinase activity. The percentage of tyrosinase inhibition was higher than $70 \%$ at $2.0 \mathrm{mg} / \mathrm{ml}$ of test concentration. An $\mathrm{IC}_{50}$ dose of WMRI_Isopropanol was approximately $1.50 \mathrm{mg} / \mathrm{ml}$. In the case of WMRI_Ethanol extract, the percentage of tyrosinase inhibition was higher than $40 \%$ at $1.0 \mathrm{mg} / \mathrm{ml}$ of treatment concentration. However, in this extract, we were unable to detect the $\mathrm{IC}_{50}$ value. The potential of tyrosinase inhibitory effect was suggested in WMRI_Isopropanol; leading to these extracts were collected to examine the biological properties and bioactive compounds in the next experiments.

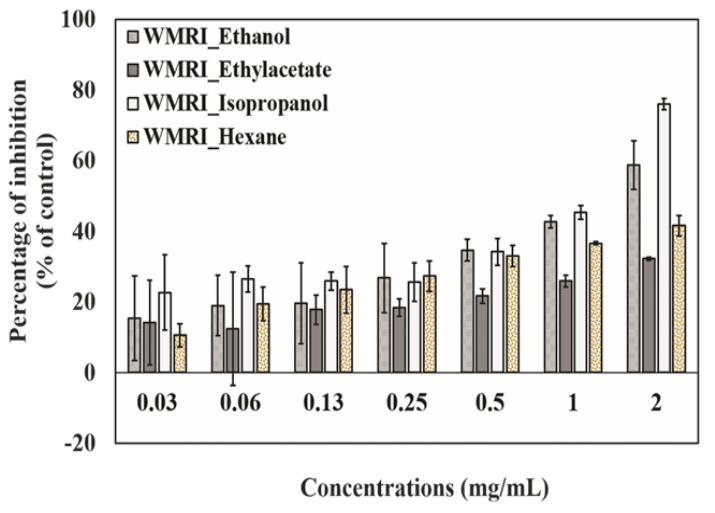

Fig. 2. Tyrosinase Inhibitory effect of the extracts; WMRI Hexane, WMRI_Ethylacetate, WMRI_Isopropanol and WMRI_ Ethanol. The results represent the percentage of inhibition which indicate by mean \pm S.D, $(n=3)$

\section{Anti-tyrosinase activity of $6 A^{*}$ fraction}

WMRI_Isopropanol was divided into two layers: (1) non-polar layer and (2) polar layer, called $6 A^{*}$. Both extracted parts inhibited tyrosinase activity in vitro. The non-polar layer showed the percentage of antityrosinase less than $40 \%$ of the test concentration (data not shown). The $\mathrm{IC}_{50}$ dose of the non-polar layer might have been higher than $0.50 \mathrm{mg} / \mathrm{ml}$. In addition, the high polarity substances in the $6 \mathrm{~A}^{*}$ fraction displayed vigorous anti-tyrosinase activity. The data was exhibited in Fig. 3. The percentage of tyrosinase inhibition was increased to $80 \%$ after being treated with $0.40 \mathrm{mg} / \mathrm{ml}$ of this extracted part. The $\mathrm{IC}_{50}$ value represented approximately $0.18 \mathrm{mg} / \mathrm{ml}$. This result indicated that the bioactive agents in $6 \mathrm{~A}^{*}$ displayed dose-dependent anti-tyrosinase activity.

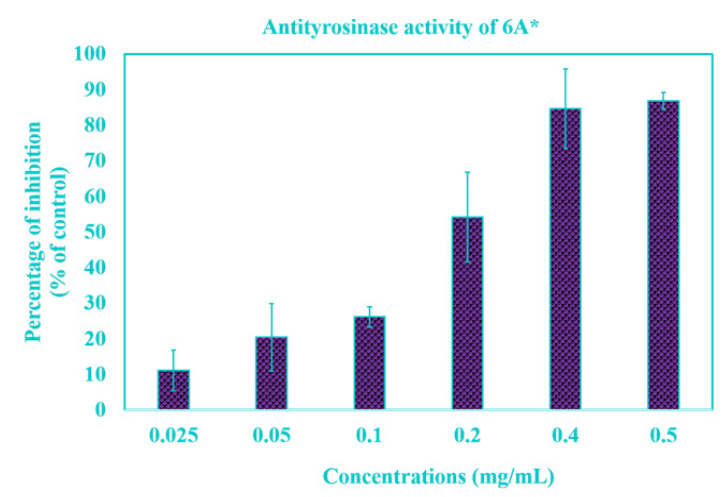

Fig. 3. Tyrosinase inhibitory effect of $6 A^{*}$ fraction. The different concentrations of this sample were treated with mushroom tyrosinase. The data of treatment test which presented the concentration, $0.2,0.4$ and $0.5 \mathrm{mg} / \mathrm{mL}$ showed the statistically significant from the control $(P<0.05)$. The $I_{50}$ value was indicated approximately $0.18 \mathrm{mg} / \mathrm{mL}$ 


\section{Antioxidation activity of $6 A^{*}$ fraction}

DPPH is the free radical that has been extensively used to assay the free radical scavenging ability of manifold specimens. The antioxidant agents are able to decrease free radicals by donation of the electron ( $\mathrm{H}$ atom) to the DPPH radical. The percentage of antioxidant activity is exhibited in Fig. 4. The result indicated that phytochemical compounds in $6 \mathrm{~A}^{*}$ displayed scavenging activity with an $\mathrm{IC}_{50}$ dose of 48.0 $\mu \mathrm{g} / \mathrm{ml}$. The increasing concentration of this sample promoted the antioxidant ability In vitro. Approximately $80 \%$ of the inhibitory activity was indicated at a test concentration higher than $50 \mu \mathrm{g} / \mathrm{ml}$.

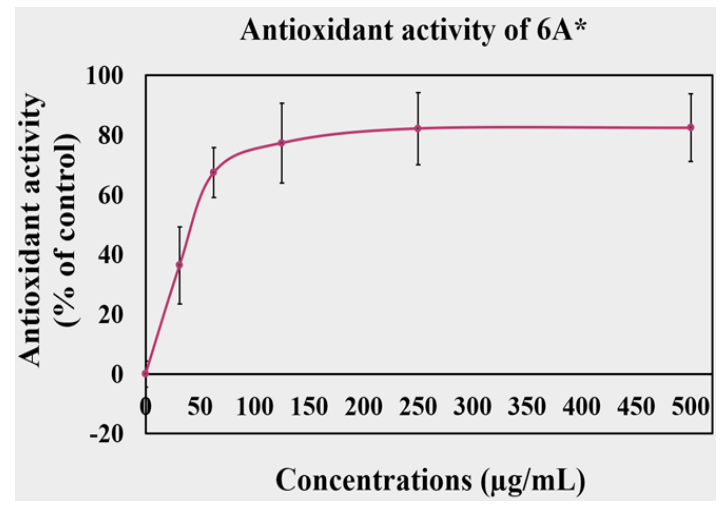

Fig. 4. The antioxidant activity of $6 A^{*}$ fraction which was determined by DPPH assay

The Cytotoxic Effect of $6 A^{*}$ in the Oral Carcinoma Cell Line (KB Cells) and Normal Human Dermal Fibroblasts Cell Lines (NHDF Cells)

The oral carcinoma cell lines (KB cells) were treated with different concentrations of the $6 A^{*}$ fraction. The percentage of viability of $K B$ cells is indicated in Fig. 5A. The treatment sample $\left(6 A^{*}\right)$ showed the cytotoxic effect in KB cells to be doseand time-dependent. The $\mathrm{IC}_{50}$ value presented approximately $1.4 \mathrm{mg} / \mathrm{ml}$ of $6 \mathrm{~A}^{*}$. Interestingly, the effect of $6 A^{*}$ in NHDF cells exhibited an $I C_{50}$ dose higher than in KB cells (Fig. 5B). This result indicated that the compounds in $6 A^{*}$ also showed very low cytotoxic effect in normal cells.

\section{Thin Layer Chromatography of $6 A^{*}$}

The $6 A^{*}$ fraction that used the high polarity condition of the mobile phase was separated. The result is presented in Fig. 6(A-C). The result presented in Fig. $6(\mathrm{~A})$ indicated that a spot of $6 \mathrm{~A}^{*}$ showed a similar $R_{f}$ value to standard gallic acid, which is associated with the results in Fig. 6(B) and $6(C)$. Moreover, the substance in $6 A^{*}$ that appeared as a green color (Fig. 6(B)) might be glycoside or glycoside derivative. Thus, $6 A^{*}$ was purified by C18 reverse-phase HPLC to analyze the type of phytochemical compounds.
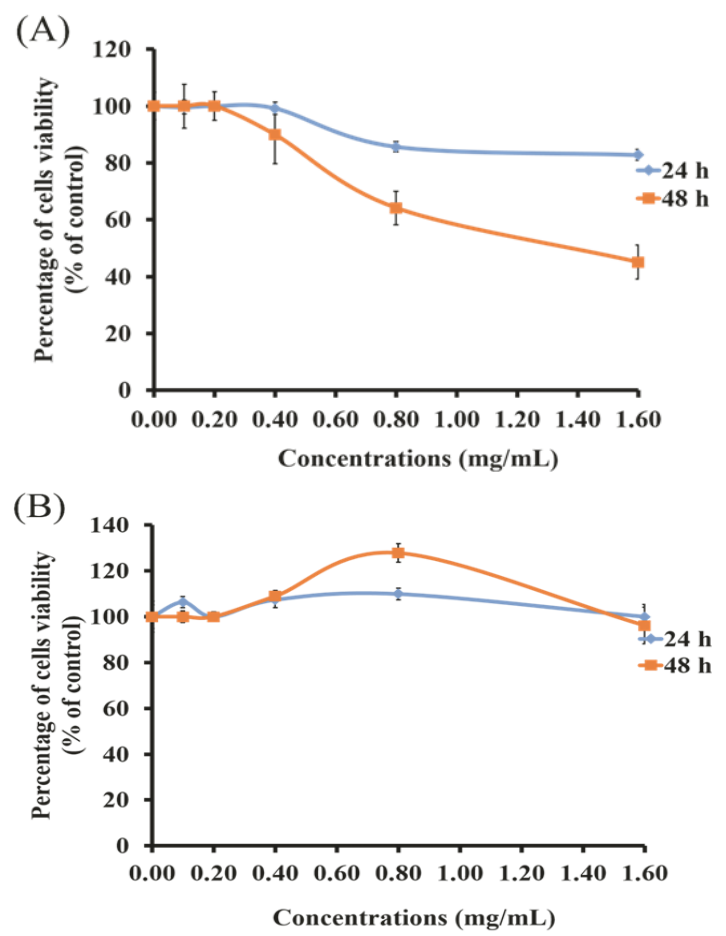

Fig. 5. The cytotoxic effect of $6 A^{*}$ on $K B$ cells $(5 A)$ and NHDF cells (5B). Both cell lines were treated with different concentration of $6 A^{\star}$ and incubated for 24 and $48 \mathrm{~h}$, respectively. The concentration, 0.8 and $1.6 \mathrm{mg} / \mathrm{mL}$ which incubated for $48 \mathrm{~h}$ presented the significant of the percentage cell viability from control $(P$ value $<0.05)$ and significant between groups of cells lines (KB cells and NHDF cells).
(A)

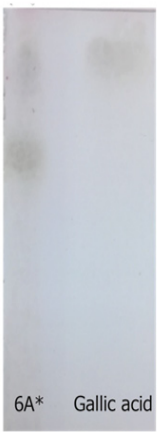

(B)

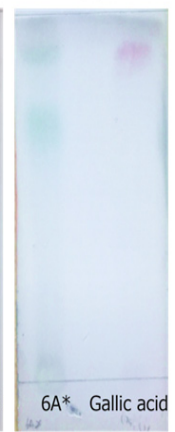

(C)

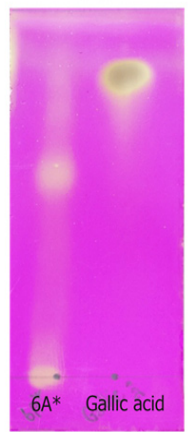

(D)

Fig. 6. Thin layer chromatography profile of treatment sample $6 A^{*}$ and gallic acid which performed using Chloroform: Methanol: $\mathrm{H}_{2} \mathrm{O}$ as mobile phase. In the presence (A), (B) and (C) were developed by $12 \% \mathrm{v} / \mathrm{v} \mathrm{H}_{2} \mathrm{SO}_{4}, 0.05 \%$ Anis-aldehyde in acid and $\mathrm{KMnO}_{4}$, respectively. Fig. 6 (D) showed the separation of $6 \mathrm{~A}$ 03 (Lane 1) and standard gallic acid (Lane 2) which the localized of the compounds were detected by Ultraviolet light $(254 \mathrm{~nm})$ 


\section{HPLC Purification Profile of $6 A^{*}$}

The chromatography profile of purified $6 \mathrm{~A}^{*}$ by $\mathrm{C} 18$ reverse-phase HPLC is shown in Fig. 7. The 12 purified peaks were collected: $6 \mathrm{~A}-01,6 \mathrm{~A}-02$, 6A-03, 6A-04, 6A-05, 6A-06, 6A-07, 6A-08, 6A-09, $6 \mathrm{~A}-10,6 \mathrm{~A}-11$, and $6 \mathrm{~A}-12$. All purified peaks were determined to exhibit tyrosinase inhibitory effect and antioxidant activity.

The Biological Properties of the Purified Peaks

The 12 purified peaks were analyzed for tyrosinase inhibitory activity. The data are shown in Table 2. There are 10 purified peaks able to inhibit tyrosinase activity in vitro: $6 \mathrm{~A}-01,6 \mathrm{~A}-02,6 \mathrm{~A}-03$, 6A-04, 6A-05, 6A-07, 6A-08, 6A-10, 6A-11, and $6 \mathrm{~A}-12$. The percentage of inhibition of each peak was higher than 70\%; in particular, 6A-03 showed strong anti-tyrosinase activity, which $103 \%$ inhibition. Furthermore, the antioxidant activity was also represented in the $6 \mathrm{~A}-02,6 \mathrm{~A}-03,6 \mathrm{~A}-04,6 \mathrm{~A}-05,6 \mathrm{~A}-$ 07, 6A-09, 6A-10, 6A-11, and 6A-12 peaks. However, this bioactivity was not detected in the $6 \mathrm{~A}-01,6 \mathrm{~A}-06$, and $6 \mathrm{~A}-08$ peaks. This result was presented in Table 3. Interestingly, approximately $80 \%$ of antioxidant activity was shown in 6A-03 and 6A-09.

\section{Type of phytochemical compounds of purified peaks}

Folin reagent was used to determine the phenolic compound in all purified peaks. A positive result was indicated by the blue-black/blue-blue light color which is associated with the dose of the phenolic compound. The result was shown in Fig. 8. Blue-black color was represented in gallic acid (positive control), 6A-09 and 6A-12, while 6A03, 6A-04, 6A-05, 6A-07, 6A-10, 6A-11 exhibited blue color. In addition, 6A-01 and 6A-02 presented blue light color. However, the purified $6 \mathrm{~A}-06$ and 6A-08 presented a similar color spot with negative control (methanol). These results indicated that most phytochemical agents in $6 \mathrm{~A}^{*}$ contained aromatic alcohol in their structures. Therefore, phenolic compounds might be the major bioactive agents in the $6 \mathrm{~A}^{*}$ fraction. Furthermore, strong inhibitory tyrosinase effect and antioxidant activity appeared in 6A-03. Therefore, this purified peak was studied the structure of the bioactive agent using proton nuclear magnetic resonance spectroscopy ( ${ }^{1} \mathrm{H}$ NMR). The ${ }^{1} \mathrm{H}$ NMR spectrum of $6 \mathrm{~A}-03$ showed only one signal at $\mathrm{d}$ 6.91 for the aromatic proton, which indicated that 1,3 , 4, 5-tetra substituted benzene ring moiety. The signals at d $8.80(1 \mathrm{H}, \mathrm{OH})$ and $9.16(2 \mathrm{H}, \mathrm{OH})$ indicated three phenolic alcohols. These data are very close to those of gallic acid in the literature ${ }^{22}$. In addition, the separation profile of purified peak $6 \mathrm{~A}-03$ by TLC exhibited the $R_{f}$ value similar to that of standard gallic acid. The result is shown in Fig. 6(D).
Table 2: The tyrosinase inhibitory effect of the purified peaks, including the percentage of tyrosinase inhibition. The symbol "+" and ""-" mean the bioactive agents of the purified peak displayed the anti-tyrosinase activity and the absent of tyrosinase inhibitory property, respectively

\begin{tabular}{lcc}
\hline Samples & $\begin{array}{c}\text { Tyrosinase } \\
\text { inhibitory effect }\end{array}$ & $\begin{array}{c}\text { Percentage of inhibition } \\
\text { (\% of control) }\end{array}$ \\
\hline $6 A-01$ & + & 99 \\
$6 A-02$ & + & 99 \\
6 A-03 & + & 104 \\
$6 A-04$ & + & 98 \\
$6 A-05$ & + & 76 \\
$6 A-06$ & - & -8 \\
$6 A-07$ & + & 100 \\
$6 A-08$ & + & 72 \\
$6 A-09$ & + & -74 \\
$6 A-10$ & + & 100 \\
$6 A-11$ & + & 99 \\
$6 A-12$ & + & 96 \\
Kojic acid & & 90 \\
\hline
\end{tabular}

Table 3: The antioxidant activity of purified peaks

\begin{tabular}{|c|c|c|c|}
\hline Samples & $\begin{array}{c}\text { Assayed } \\
\text { Concentration } \\
100 \mu \mathrm{g} / \mathrm{mL}\end{array}$ & $\begin{array}{l}\text { Antioxidant } \\
\text { activity }\end{array}$ & $\begin{array}{c}\text { Percentage of } \\
\text { antioxidant activity (\%) }\end{array}$ \\
\hline $6 A-01$ & 100 & ND & ND \\
\hline $6 \mathrm{~A}-02$ & 100 & + & 47 \\
\hline $6 \mathrm{~A}-03$ & 46 & + & 80 \\
\hline $6 \mathrm{~A}-04$ & 28 & + & 33 \\
\hline $6 \mathrm{~A}-05$ & 111 & + & 65 \\
\hline $6 A-06$ & 43 & ND & ND \\
\hline $6 \mathrm{~A}-07$ & 60 & + & 69 \\
\hline $6 A-08$ & 29 & ND & ND \\
\hline $6 A-09$ & 383 & + & 80 \\
\hline $6 A-10$ & 106 & + & 74 \\
\hline $6 A-11$ & 113 & + & 76 \\
\hline $6 \mathrm{~A}-12$ & 169 & + & 72 \\
\hline
\end{tabular}
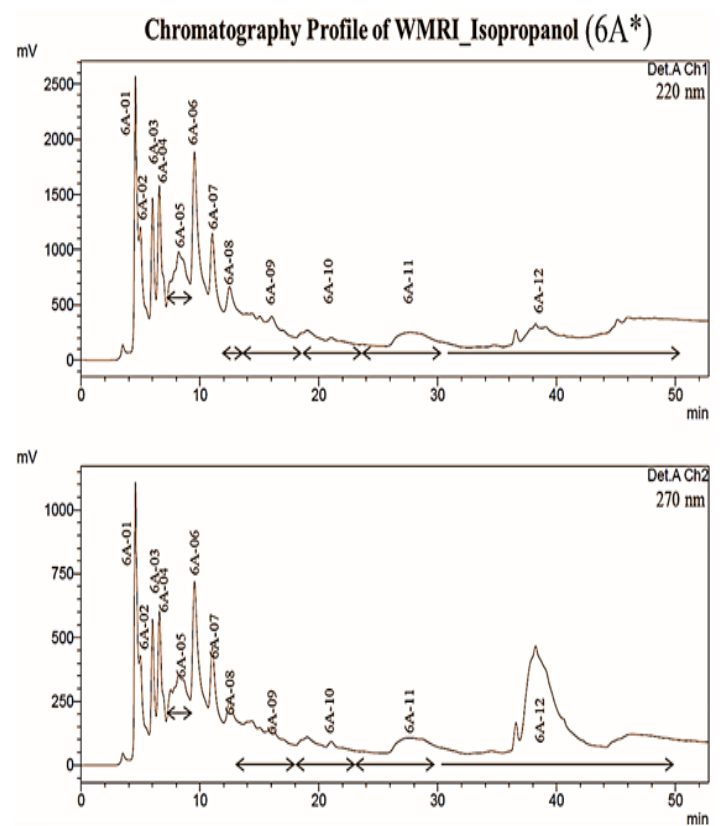

Fig. 7. Elution profile of purification treatment sample $6 A^{*}$ by C18 reverse phase high pressure column chromatography (HPLC). Time program of separation was showed in Table 1. The absorbance value was measured at $220 \mathrm{~nm}$ and $270 \mathrm{~nm}$ 


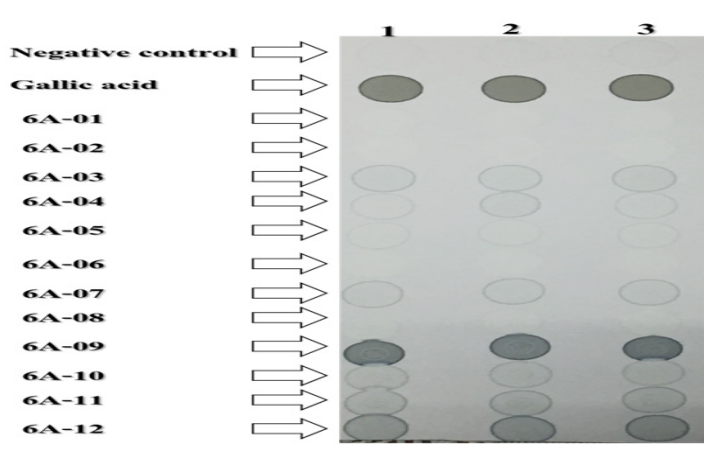

Fig. 8. Determination of phenolic alcohol of purified peaks using folin reagent. The data are presented on a silica sheet. Blue-black and blue, including blue light color, represent the phenol ring or phenolic alcohol in their structure

\section{DISCUSSION}

Safety is an important target for developing health care products, especially cosmetics and food, including chemotherapeutic agents. In this study, plant extracts or natural compounds have been promoted for use as the active ingredients in various industrial products ${ }^{23}$. However, the lack of application of phytochemical agents from ripe wild mango (S. pinnata) fruit in cosmetics, food products, and cancer prevention encouraged us to implement this study.

Hyperpigmentation is a problem of the skin related to the melanogenesis process ${ }^{24}$ and associated with the catalytic activity of tyrosinase enzyme. Thus, the suppression of tyrosinase activity is a goal to decrease the melanin production of cells. According to previous reports, many natural products and synthetic compounds are used for subjection as the active components in whitening products $^{1,23}$. However, high concentration of some anti-tyrosinase substances also showed side effects due to limitations in the application used. In this work, we indicated that the bioactive components from the extracted part of ripe wild mango fruit showed potential tyrosinase inhibitory effect, as well as antioxidant and anticancer activities. The polyphenolic/phenolic compounds are the major phytochemical substances found in this report.

Polyphenolic compounds are the major group of secondary metabolites in plants ${ }^{25}$. There are many kinds of phenolic and flavonoid compounds that have indicated the ability to exhibit tyrosinase inhibitory effects as well as antioxidant and anticancer activities ${ }^{23,26,27,28}$. Our data showed that gallic acid is a phenolic compound represented in the $6 A^{*}$ fraction and purified peak $6 \mathrm{~A}-03$. It has been found in many kinds of plants, including the genus Spondias ${ }^{9}$. It exhibits many strong bioactivities: for example, antimicrobial, antioxidant, anticancer and anti-inflammatory activities. Moreover, gallic acid also showed tyrosinase inhibitory activity. It displayed as a noncompetitive inhibitor in mushroom tyrosinase ${ }^{29}$. Therefore, the tyrosinase inhibitory effect of $6 A^{*}$ and 6A-03 also participated in the presentation of gallic acid, which is related to previous reports. However, the phytochemical compounds of other purified peaks that showed anti-tyrosinase activity will be analyzed in future work.

Additionally, phenolics and flavonoids displayed a central role in antioxidant activity ${ }^{27}$. Recent reports have indicated that ROS can enhance oxidative damage due to the disordered biomolecules in cells. Moreover, they were able to activate the enzyme's activity of elastase, hyaluronidase, collagenase, which digested biomolecules (elastin, hyaluronic acid, and collagen) in the extracellular matrix of cells, leading to the wrinkled appearance of the skin ${ }^{1}$. Furthermore, ROS can promote the activity of tyrosinase. This enzyme activated the melanogenesis process, which causes hyperpigmentation or melasma. Therefore, antioxidant agents play a key role in biomolecular disorder and aging prevention. The mechanism of antioxidation of phenolics and flavonoids has been explained by the fact that these compounds use the hydroxyl group in their benzene ring structure to donate an electron (H-atom) to free radicals ${ }^{30}$ due to the biomolecules in cells being protected from destruction by free radicals. Therefore, the strong antioxidant activity reported in our work might relate to the major polyphenolic agents in $6 \mathrm{~A}^{*}$.

In food fields, tyrosinase is an enzyme that catalyzes the browning reactions in food products due to the nutritional quality being lost in storage. Thus, the methods that enable stopping the activity of tyrosinase enzyme are interesting and identified. Determining capable compounds is a method used to interrupt tyrosinase activity. However, the inhibition of enzymatic browning by chemical compounds has limited application in the food system. According to previous reports, sulfiting substances have been used for suppression of the enzymatic browning of 
seafood and agricultural products. These agents can be used in some food products, controlled by the Food and Drug Administration (FDA). Thus, food industries still continually determine the enzymatic browning inhibitors from natural sources to increase safety and avoid side effects. In our work the phytochemical compounds that showed anti-tyrosinase activity and presented very low cytotoxicity with normal cells could be developed for use as food additives for inhibition of enzymatic browning of food products in the future ${ }^{23}$.

Recent reports have indicated that most chemotherapeutic compounds also exhibited side effects with normal cells, leading to unsatisfactory cancer treatments. To decrease the side effect of chemotherapeutic therapy, new anticancer agents have been identified from many sources ${ }^{31,32}$. The selective property of bioactive compounds plays a key role in decreasing side effects of cancer treatments in normal cells ${ }^{33}$. Our report suggested that the bioactive compounds in $6 A^{*}$ showed very low cytotoxic effect in NHDF cells. These substances might be able to be used in discriminating between cancer cells and normal cells. Interestingly, polyphenolic compounds are the main group found in $6 \mathrm{~A}^{*}$, including gallic acid. Previous studies have indicated that gallic acid exhibited anticancer activity in many types of cancer cells. Additionally, it presented no cytotoxic effect with primary cultured hepatocytes and macrophages of rats ${ }^{23,34}$. These results indicate that gallic acid is a phenolic compound that shows a selective property. Thus, gallic acid is studied widely for development as a cancer therapeutic agent. Chaudhuri and co-workers reported on gallic acid and methyl gallate isolated from the ethyl acetate extraction of $S$. pinnata's bark. Both agents showed a cytotoxic effect on human glioblastoma cell line
(U87). ${ }^{13}$ Moreover, gallic acid can enhance G0/G1 phase arrest and apoptosis in human leukemia HL60 cells by inhibiting cyclin $\mathrm{D}$ and $\mathrm{E}$ and activating the mitochondria-dependent pathway ${ }^{35}$. Herein, it is possible that the cytotoxic effect in KB cells may be associated with the pharmacological property of gallic acid. However, the anticancer activity of other phytochemical agents in our work will be analyzed in future work.

Overall it can be concluded that ripe wild mango fruit is a source of bioactive compounds that display the tyrosinase inhibitory effect, as well as antioxidant and anticancer properties. Importantly, these compounds exhibited very low cytotoxicity with NHDF cells. Therefore, these phytochemical agents could be developed for an application used in cosmetic products, food additives, or cancer therapy in the future.

\section{ACKNOWLEDGEMENT}

We would like to express our deepest and most sincere gratitude to the National Research Council of Thailand (NRCT), which supported the scholarship for this research. Additionally, the Department of Chemistry, Faculty of Science and Technology, Rajamangala University of Technology Thanyaburi, Faculty of Dentistry Khon Kaen University, Department of Applied Chemistry, National Pingtung University accommodated the research facilities.

\section{Conflict of interest}

We wish to confirm that there are no known conflicts of interest associated with this publication, and there has been no significant financial support for this work that could have influenced its outcome.

\section{REFERENCES}

1. Garg, C.; Khurana, P.; Garg, M. Molecular mechanisms of skin photoaging and plant inhibitors. Int. J. Green. Pharmacy., 2017, 11(2), S217-S232.

2. Nema, T.; Chan, E.C.; Ho, P.C. Efficiency of a miniaturized silica monolithic cartridge in reducing matrix ions as demonstrated in the simultaneous extraction of morphine and codeine from urine samples for quantification with liquid chromatography-tandem mass spectrometry (LC-MS/MS). J. Mass. Spectrom., 2011, 46(9), 891-900.

3. Piwowarski, J.P.; Kiss, A.K.; KozłowskaWojciechowska, M. Anti-hyaluronidase and anti-elastase activity screening of tanninrich plant materials used in traditional Polish medicine for external treatment of diseases with inflammatory background. $J$. Ethnopharmacol., 2011, 137(1), 937-941. 
4. Thring, T.S.; Hili, P.; Naughton, D.P. Anticollagenase, anti-elastase and anti-oxidant activities of extracts from 21 plants. BMC. Complement. Altern. Med., 2009, 9(1), 27-11.

5. Sanni, D.M.; Omotoyinbo, O.V. Phytochemical Screening, Tyrosinase inhibitory effects and kinetics of cam wood dye extracts. Adv. Biochem., 2016, 4(2), 16-20.

6. Hussain, R.; Shaukat, Z.; Khan, M.; Saint, R.; Gregory, S.L. Phosphoenolpyruvate carboxykinase maintains glycolysis-driven growth in Drosophila tumors. Sci Rep., 2017, $7(1), 1-11$.

7. Kasote, D.M.; Katyare, S.S.; Hegde, M.V.; Bae, $\mathrm{H}$. Significance of antioxidant potential of plants and its relevance to therapeutic applications. Int. J. Biol. Sci., 2015, 11(8), 982-991.

8. Li, N.A.; Li, S.; Zhang, Y.J.; Xu, X.R.; Chen, Y.M.; Li, H.B. Resources and biological activities of natural polyphenols. Nutrients., 2014, 6, 6020-6047.

9. Sameh, S.; Al-Sayed, E.; Labib, R.M.; Singab, A.N. Genus Spondias: A Phytochemical and pharmacological review. Evid Based Complement Alternat Med., 2018, 4, 1-13.

10. Hazra, B.; Biswas, S.; Mandal, N. Antioxidant and free radical scavenging activity of Spondias pinnata. BMC. Complement. Altern. Med., 2008, 8, 1-10.

11. Cabral, M.; Cheng, X.; Singh, S.; Ivessa, A.S. Absence of non-histone protein complexes at natural chromosomal pause sites results in reduced replication pausing in aging yeast cells. Cell. Rep., 2016, 17(7), 1747-1754.

12. Arif, M.; Hussain, N.;Yasmeen, A. Morphological and physiological response of cotton to exogenous application of growth regulators. Agr. Res. J., 2016, 4(8), 467-477.

13. Chaudhuri, R.; Knoblauch, K.; Gariel, M.A.; Kennedy, H.; Wang, X.J. A large-scale circuit mechanism for hierarchical dynamical processing in the primate cortex. Neuron., 2015, 88(2), 419-431.

14. Adhikari, T.; Kundu, S.; Meena, V.; Subba Rao, A. Utilization of nano rock phosphate by maize (Zea mays L.) crop in a vertisol of central India. Agr. Sci. Tech., 2014, 4, 384-394.

15. Singh, R.B.; Saxena, V.K. Chemical investigation on Spondias mangifera. The Institute of Chemists (India)., 1976, 48, 299.
16. Punyatong, M.; Pongpiachan, P.; Pongpiachan, P.; Kaladee, D.; Mankhetkorn, S. Cytotoxicity of crude extract proanthocyanidin from purple glutinous rice bran (Oryza sativa L.) Kum Doi Saket compared with cyanidin 3-glucosideon X63 myeloma cancer cells line. Kasetsart. $J$. (Natural Science)., 2008, 42(4), 676-681.

17. Long, H.H.; Schmidt, D.D.; Baldwin, I.T. Native bacterial endophytes promote host growth in a species-specific manner; phytohormone manipulations do not result in common growth responses. PLOS. One., 2008, 3(7), 1-10.

18. Chen, Y.; Lawless, C.; Gillespie, C.S.; Wu, J.; Boys, R.J.; Wilkinson, D.J. CaliBayes and BASIS: integrated tools for the calibration, simulation and storage of biological simulation models. Brief. Bioinform., 2010, 11(3), 278-289.

19. Mosmann, T. Rapid colorimetric assay for cellular growth and survival: application to proliferation and cytotoxicity assays. $J$. Immunol. Methods., 1983, 65 (1-2), 55-63.

20. Patathananone, S.; Thammasirirak, S.; Daduang, J.; Chung, J. G.; Temsiripong, Y.; Daduang, S. Inhibition of HeLa cells metastasis by bioactive compounds in crocodile (Crocodylus siamensis) white blood cells extract. Environ. Toxicol., 2016, 31(11), 1329-1336.

21. Dewanto, V.; Wu, X.; Adom, K. K.; Liu, R. H. Thermal processing enhances the nutritional value of tomatoes by increasing total antioxidant activity. J. Agr. Food. Chem. 2002, 50(10), 3010-3014.

22. Xu, L.; Gong, W.; Cusack, S. A.; Wu, H.; Loovers, H. M.; Zhang, H.; Perrett, S.; Jones, G. W. The $\beta 6 / \beta 7$ region of the Hsp70 substrate-binding domain mediates heatshock response and prion propagation. Cell. Mol. Life. Sci., 2018, 75(8), 1445-1459.

23. Kim, Y. J.; Uyama, H. Tyrosinase inhibitors from natural and synthetic source: structure, inhibition mechanism and prospective for the future. Cell. Mol. Life Sci., 2005, 62, 1707-1723.

24. Popoola, O. K.; Marnewick, J. L.; Rautenbanch, F.; Ameer, F.; Iwuoha, E. I.; Hussein, A. A. Inhibition of oxidative stress and skin agingrelated enzymes by prenylated chalcones and other flavonoids from Helichrysum teretifolium. Molecules., 2015, 20, 7143- 7155. 
25. Pedrosa, T. D.; Barros, A. O.; Nogueira, J. R.; Fruet, A. C.; Rodrigues, I. C.; Calcagno D. Q.; Smith, M. A.; de Souza, T. P.; Barros, S. B.; de Vasconcellos, M. C.; Silva, F. M.; Koolen, H. H.; Maria-Engler, S. S.; Lima, E. S. Anti-wrinkle and anti-whitening effects of jucá (Libidibia ferrea Mart.) extracts. Arch. Dermatol. Res., 2016, 308(9), 643 -654.

26. Kandaswami, C.; Lee, L. T.; Lee, P. P.; Hwang, J. J.; Ke, F. C.; Huang, Y. T.; Lee, M. T. The antitumor activities of flavonoids. In vivo., 2005, 19, 895 - 910.

27. Kim, Y. J. Antimelanogenic and antioxidant properties of gallic acid. Biol. Oharm. Bull., 2007, 30, 1052-1055.

28. George, V. C.; Dellaire, G.; Rupasinghe, H. P.V. Plant flavonoids in cancer chemoprevention: role in genome stability. J. Nutr. Biochem., 2017, 45, 1 - 14.

29. Gheibi, N.; Hosseini Zavareh, S.; Rezaei Behbahani, G. R.; Haghbeen, K.; Siratisabet, M.; Ilghari, D.; Goodarzvand, K. Comprehensive kinetic and structural studies of different flavonoids inhibiting diphenolase activity of mushroom tyrosinase. Appl. Biochem. Microbiol., 2016, 52(3), 304-310.

30. Pietta, P. G. Flavonoids as antioxidants. J. Nat. Prod., 2000, 63, 1035-1042.
31. Dharap, S. S.; Wang, Y.; Chandna, P.; Khandare, J. J.; Qiu, B.; Gunaseelan, S.; Sinko, P. J.; Stein, S.; Farmanfarmaian, A.; Minko, T. Tumor-specific targeting of an anticancer drug delivery system by LHRH peptide. Proc. Natl. Acad. Sci. U S A., 2005, 102(36), 12962-12967.

32. Lin, J. P.; Yang, J. S.; Chang, N. W.; Chiu, T. H.; Su, C. C.; Lu, K. W, Ho, Y. T.; Yeh, C. C.; Mei, D.; Lin, H. J.; Chung, J. G. GADD153 mediates berberine-induced apoptosis in human cervical cancer CaSki cells. Anticancer. Res., 2007, 27, 3379-3386.

33. Allen, T. M.; Cullis, P. R. Drug delivery systems: Entering the mainstream. Sci., 2004, 303, 1818-1822.

34. Sun, G.; Zhang, S.; Xie, Y.; Zhang, Z.; Zhao, W. Gallic acid as a selective anticancer agent that induces apoptosis in SMMC-7721 human hepatocellular carcinoma cells. Oncol. Lett., 2016, 11(1), 150-158.

35. Yeh, T.C.1.; Liu, H. L.; Chung, C. S.; Wu, N.Y.; Liu, Y. C.; Cheng, S. C. Splicing factor Cwc22 is required for the function of Prp2 and for the spliceosome to escape from a futile pathway. Mol. Cell. Biol., 2011, 31(1), 43-53. 